\title{
LA RESPONSABILIDAD DE LOS ADMINISTRADORES.
}

THE RESPONSIBILITY OF THE DIRECTORS.

JOSE MIGUEL ZURITA VICIOSO

Abogado $\mathrm{n}^{\circ}$ 5.448 ICAGR

Doctorando Departamento Derecho Mercantil y Derecho Romano

Universidad de Granada

RESUMEN: Los administradores de las sociedades de capital han de actuar, en el ejercicio de sus funciones, cumpliendo con los deberes que le son exigidos por Ley porque, de lo contrario, su patrimonio personal puede verse expuesto al resarcimiento de los daños que hayan ocasionado a la propia sociedad que representan, a sus socios o a terceros. Por ello, es importante conocer qué acciones pueden instarse contra los administradores y cuáles son las causas que éstos pueden alegar para quedar exonerados.

PALABRAS CLAVE: administrador, responsabilidad, acción social, acción individual.

ABSTRACT: Directors of corporations must act in the exercise of their company functions, fulfilling the duties that are required by law because, otherwise, their personal assets may be exposed to compensation for the damages they have caused to the society they are representing, its partners or third parties. It is therefore important to know what actions can be urged against the Directors and the causes they may claim to be exempted.

KEY WORDS: director, responsibility, social action, individual action.

SUMARIO: INTRODUCCIÓN. $\quad$ I.- PRESUPUESTOS DE LA RESPONSABILIDAD. II.- ALCANCE DE LA RESPONSABILIDAD. III.ACCIÓN SOCIAL DE RESPONSABILIDAD. IV.- ACCIÓN INDIVIDUAL DE RESPONSABILIDAD. V.- SUPUESTO DE RESPONSABILIDAD DEL ART. 367.1 LSC. VI. RESPONSABILIDAD DEL ADMINISTRADOR EN EL ÁMBITO CONCURSAL. VII.- RESPONSABILIDAD DEL ADMINISTRADOR DE UNA SOCIEDAD EN FORMACIÓN. VIII.- CONCLUSIONES. 


\section{I.- Introducción.}

Los administradores de las sociedades de capital son los encargados de actuar en nombre y representación de la sociedad que dirigen o administran cumpliendo con los deberes que vienen establecidos en los artículos 225 y ss. de la Ley de Sociedades de Capital, aprobada por el Real Decreto Legislativo 1/2010, de 2 de julio (en adelante LSC). Los administradores serán responsables si incumplen estos deberes y ello provoca un daño directo a la sociedad, afectando indirectamente a los socios o a terceros, o bien lesionando directamente los intereses de unos y otros. Se trata de una responsabilidad de naturaleza civil, distinta de la responsabilidad administrativa, fiscal, penal o de cualquier otra índole en la que pudieran incurrir por su actuación al frente de la sociedad ${ }^{1}$

Recientemente, la Ley 31/2014, de 3 de diciembre, por la que se modifica la Ley de Sociedades de Capital para la mejora del gobierno corporativo (en adelante Ley 31/2014), que entró en vigor el pasado 24 de diciembre de 2014, ha modificado, en lo referente a los deberes de los administradores, los artículos 225 a 230 y el 232 de la LSC y ha incluido el nuevo artículo 241. bis de la LSC referente a la prescripción de las acciones de responsabilidad que se pueden seguir contra los administradores ${ }^{2}$.

La LSC le dedica el Capítulo V del Título VI a regular este sistema de responsabilidad jurídico-privada de los administradores, que ha obtenido, en opinión unánime de la doctrina mercantilista, mayor trascendencia práctica desde el cambio de regulación realizado por la Ley de Sociedades Anónimas de 1989 respecto a la establecido Ley de Sociedades Anónimas de 1951 y otros precedentes legislativos que mostraban una

\footnotetext{
${ }^{1}$ En este sentido, AA.VV. Lecciones de Derecho Mercantil. (Dir. Menéndez, A. y Rojo, A.) Navarra, 2014; Quijano González, J. La responsabilidad de los administradores de la sociedad anónima. Valladolid, 1985.

${ }^{2}$ Ley 31/02014, de 3 de diciembre, por la que se modifica la Ley de Sociedades de Capital para la mejora del gobierno corporativo, que entró en vigor el 24 de diciembre de 2014 y que señala en su Exposición de Motivos que "las modificaciones del Texto Refundido de la Ley de Sociedades de Capital... que aquí se contienen pueden agruparse en dos categorías: las que se refieren a la junta general de accionistas y las que tienen que ver con el consejo de administración”. Igualmente, en lo que se refiere a la regulación de los deberes del administrador indica que se pretende “... una tipificación más precisa de los deberes de diligencia y lealtad y de los procedimientos que se deberían seguir en caso de conflicto de interés...".
} 
postura excepcionalmente laxa o benigna hacia los administradores en casos de culpa leve o levísima ${ }^{3}$.

\section{Presupuestos de la responsabilidad.}

Actualmente, el régimen de responsabilidad de los administradores es común a las sociedades anónimas y limitadas estableciendo la nueva redacción del artículo 236.1 LSC dada por la Ley 31/2014 en cuanto a los presupuestos para que exista responsabilidad de los administradores, lo siguiente:

“1. Los administradores responderán frente a la sociedad, frente a los socios y frente a los acreedores sociales, del daño que causen por actos u omisiones contrarios a la ley o a los estatutos o por los realizados incumpliendo los deberes inherentes al desempeño del cargo, siempre y cuando haya intervenido dolo o culpa.

La culpabilidad se presumirá, salvo prueba en contrario, cuando el acto sea contrario a la ley o a los estatutos sociales.

De la lectura del precepto y siguiendo la interpretación dada por los autores Sánchez Calero, F. y Sánchez-Calero Guilarte, J. ${ }^{4}$, opinamos que no es suficiente para que el administrador incurra en responsabilidad que su actuación produzca un daño sino que también han de exigirse otros presupuestos que pasamos a analizar a continuación:

El primero de los presupuestos para generar la responsabilidad de los administradores es que el daño que produce su actuación sea sufrido por la propia sociedad, lo que le legitima para interponer la acción social de responsabilidad.

El segundo presupuesto sería el incumplimiento de las obligaciones por parte de los administradores debido a actos u omisiones contrarios a la Ley o los estatutos o por los realizados incumpliendo los deberes inherentes al desempeño del cargo. Se trata de una remisión al estatuto de deberes de los administradores contenidos en los arts. 225 y ss.

\footnotetext{
3 Broseta Pont, M. y Martínez Sanz, F., Manual de Derecho Mercantil. Madrid, 2014, p. 505 y ss. Para mayor información sobre la regulación anterior en materia de responsabilidad de los administradores: Farrián Farriol, J. La responsabilidad de los administradores en la administración societaria. Barcelona, 2004.

${ }^{4}$ Sánchez Calero, F. / Sánchez-Calero Guilarte, J., Instituciones de Derecho Mercantil. Volumen I. Navarra, 2013, págs. 528 y ss.; Neila Neila, J.M. La responsabilidad de los administradores en las sociedades de capital. Madrid, 1995; Farrán Farriol, J., La responsabilidad de los administradores en la administración societaria. Barcelona, 2004;
} 
LSC que, que como hemos señalado más arriba, han sido recientemente reformados por la Ley $31 / 2014$.

Respecto a la anterior redacción del art 236.1 de la $\mathrm{LSC}^{5}$, Cruz Rivero, D. señalaba que, aparentemente, se distinguían dos presupuestos distintos generadores de responsabilidad: a) la actuación u omisión contraria a la Ley o los estatutos y b) la actuación u omisión incumpliendo los deberes inherentes al cargo ${ }^{6}$. En realidad, señalaba el autor, no existía propiamente una separación de ambos supuestos pues, entre los deberes inherentes al cargo está el cumplimiento de lo dispuesto en la Ley o los estatutos (art. 226 in fine y actualmente en el artículo 225.1 de la LSC $^{7}$ ) y, por tanto, cuando incumpla la Ley o los estatutos se habrán incumplido los deberes inherentes al cargo y si se actúa negligentemente - incumpliendo los deberes del cargo - también se habrá actuado ilegalmente. También era contrario Cruz Rivero a la idea de no exigir culpa cuando se produjese una actuación del administrador contraria a la Ley o a los estatutos y, sin embargo, cuando el administrador incumplía los deberes inherentes al cargo se había de probar al menos la negligencia de aquél. En ese mismo sentido, se posicionan Broseta Pont, M. y Martínez Sanz, F. al señalar que aunque sea leve, en todo incumplimiento de una norma por parte del administrador debe existir culpa para que éste incurra en responsabilidad ${ }^{8}$. Pues bien, consideramos resuelta esta cuestión por la nueva redacción del art. 236.1 LSC que especifica que esa responsabilidad se exigirá

\footnotetext{
${ }^{5}$ Redacción del artículo 236.1 de la LSC antes de ser reformado por Ley 31/02014, de 3 de diciembre, por la que se modifica la Ley de Sociedades de Capital para la mejora del gobierno corporativo, que entró en vigor el 24 de diciembre de 2014: "los administradores de derecho o de hecho como tales, responderán frente a la sociedad, frente a los socios y frente a los acreedores sociales, del daño que causen por actos u omisiones contrarios a la ley o a los estatutos o por los realizados incumpliendo los deberes inherentes al desempeño del cargo".

${ }^{6}$ Cruz Rivero, D., La administración de la sociedad en Derecho Mercantil. Las sociedades mercantiles. (Coord. Jiménez Sánchez, G.J. y Díaz Moreno, A). Madrid, 2013, págs. 542 y ss.

${ }^{7}$ El nuevo artículo 226 guarda equivalencia con el actual artículo 227 y no con la redacción del anterior artículo 226. Es en la nueva redacción del artículo 225.1 donde se le exige a los administradores, además de la diligencia de un ordenado empresario, la obligación de cumplir con los deberes impuestos por las leyes y los estatutos.

También es de destacar que el apartado segundo del art. 225 LSC le exige a los administradores una "dedicación adecuada" en el sentido de que deben ser conocedores y partícipes de la marcha de la sociedad teniendo una participación más activa, no pudiendo, por tanto, alegar como causa de exoneración de su responsabilidad el desconocimiento. Siguiendo en la misma línea, añade el apartado tercero del mismo precepto "el deber de exigir y el derecho de recabar de la sociedad la información necesaria que le sirva (al administrador) para el cumplimiento de sus obligaciones".

${ }^{8}$ Broseta Pont, M. y Martínez Sanz, F., Manual de Derecho Mercantil. Madrid 2014, op. cit., pág.506.
} 
"siempre y cuando haya intervenido dolo o culpa". A continuación, en el siguiente párrafo establece una presunción iuris tantum de la culpabilidad en la actuación del administrador "cuando el acto sea contrario a la ley o a los estatutos sociales"9.

El tercer presupuesto consiste en la exigencia de una relación de causalidad entre los dos presupuestos anteriores, es decir, para considerar culpable la actuación del administrador ha de existir relación de causalidad entre su actuación ilícita y el daño producido. Como señala Cruz Rivero, D., se ha de seguir un criterio de imputación objetiva, no siendo suficiente la mera causalidad natural sino que deberá determinarse si ésta es suficiente para que nazca en el causante la obligación de resarcir el daño ${ }^{10}$.

Y por último, como cuarto presupuesto, deberá cuantificarse económicamente el daño producido por la actuación u omisión del administrador, siendo de prueba obligatoria para el actor que interponga la acción judicial que, en cada caso, corresponda.

Una vez examinados estos presupuestos, queremos señalar que, en la práctica procesal, es imprescindible probarlos y esta labor recae en la parte actora que insta la acción de responsabilidad. Es cierto que en los actos contrarios a la Ley o los estatutos bastará que el actor pruebe que lo son para que se presuma la culpa del administrador y será éste el obligado a probar la ausencia de la misma ${ }^{11}$.

\section{II.- Alcance de la responsabilidad.}

La nueva dicción de los apartados 2 a 5 del art.236 de la LSC aborda la extensión subjetiva de la responsabilidad y, al respecto, señalan:

“2. En ningún caso exonerará de responsabilidad la circunstancia de que el acto o acuerdo lesivo haya sido adoptado, autorizado o ratificado por la junta general.

\footnotetext{
${ }^{9}$ Nueva redacción del art. 236.1 LSC "Los administradores responderán frente a la sociedad, frente a los socios y frente a los acreedores sociales, del daño que causen por actos u omisiones contrarios a la ley o a los estatutos o por los realizados incumpliendo los deberes inherentes al desempeño del cargo, siempre y cuando haya intervenido dolo o culpa.

La culpabilidad se presumirá, salvo prueba en contrario, cuando el acto sea contrario a la ley o a los estatutos sociales."

${ }^{10}$ Cruz Rivero, D., La administración de la sociedad en Derecho Mercantil. Las sociedades mercantiles. (Coord. Jiménez Sánchez, G.J. y Díaz Moreno, A.). Madrid, 2013, op. cit., pág. 544.

${ }^{11}$ Para profundizar en regulación anterior sobre la materia, Alonso Ureba, A., "Presupuestos de la responsabilidad social de los administradores de una sociedad anónima”. Revista de Derecho Mercantil nº198, 1990, págs. 639 y ss.
} 
3. La responsabilidad de los administradores se extiende igualmente a los administradores de hecho. A tal fin, tendrá la consideración de administrador de hecho tanto la persona que en la realidad del tráfico desempeñe sin título, con un título nulo o extinguido, o con otro título, las funciones propias de administrador, como, en su caso, aquella bajo cuyas instrucciones actúen los administradores de la sociedad.

4. Cuando no exista delegación permanente de facultades del consejo en uno o varios consejeros delegados, todas las disposiciones sobre deberes y responsabilidad de los administradores serán aplicables a la persona, cualquiera que sea su denominación, que tenga atribuidas facultades de más alta dirección de la sociedad, sin perjuicio de las acciones de la sociedad basadas en su relación jurídica con ella.

5. La persona física designada para el ejercicio permanente de las funciones propias del cargo de administrador persona jurídica deberá reunir los requisitos legales establecidos para los administradores, estará sometida a los mismos deberes y responderá solidariamente con la persona jurídica administrador”.

A tenor de lo establecido en estos apartados, pasaremos a tratar específicamente algunas de las figuras de mayor relevancia en lo que al alcance de la responsabilidad de los administradores se refiere y que mayor controversia han generado tanto para la doctrina como para la jurisprudencia. Así, trataremos la figura del administrador de hecho que por primera vez ha sido definido por el legislador a través de la Ley 31/2014 y abordaremos igualmente el carácter solidario de la responsabilidad de los miembros del órgano de administración ${ }^{12}$.

\section{A) Administrador de hecho.}

Los ya desaparecidos artículos 133 de la Ley de Sociedades Anónimas y 69 de la Ley de Sociedades de Responsabilidad Limitada, tras ser modificados por la Ley 26/2003, de 17 de Julio, Ley de Transparencia y el anterior artículo 236 LSC extendían el régimen de responsabilidad del administrador, que venimos tratando, al administrador de

\footnotetext{
${ }^{12}$ Cfr., entre otros, con AA.VV., La responsabilidad de los administradores, 4ª . Ed. (Dir. Rojo, A. y Beltrán, E.). Valencia, 2011. ; AA.VV., La responsabilidad de los administradores de sociedades de capital (Coord. Guerra, G.). Madrid, 2011.
} 
hecho ${ }^{13}$. Sin embargo, ninguno de estos preceptos contenía una definición de administrador de hecho aunque sí afirmaban expresamente que el administrador de hecho responderá, de igual forma que el administrador de derecho, frente a la sociedad, sus accionistas y acreedores por actos contrarios a la Ley o los estatutos o que implicaran el incumplimiento de los deberes legales de quienes formalmente sean administradores. Para encontrar una definición de la figura del administrador de hecho, debíamos acudir a otras disposiciones legales como el Código Penal, en sus arts. 290 a 297 que regulan los delitos societarios o bien a los pronunciamientos de los Tribunales donde sí gozábamos de una definición del administrador de hecho unánimemente aceptada por la jurisprudencia, tanto en el orden penal $^{14}$ como en el orden civil ${ }^{15}$.

Consideramos de especial interés por su claridad la Sentencia de la Audiencia Provincial de La Coruña, Sección Cuarta, núm. 312/2011, de 6 de julio (JUR 2011/319319) al señalar que "las notas definitorias del administrador de hecho son las siguientes: a) elemento esencial es la autonomía o falta de subordinación a un órgano de la administración social, de tal modo que pueda razonablemente entenderse que esa persona, al margen de un nombramiento formal o regular, está ejerciendo en la práctica cotidiana las funciones del poder efectivo de gestión, administración y gobierno de que se trate, asumiendo la sociedad los actos de esa persona como vinculantes para ella y por tanto, como expresión de la voluntad social; b) la habitualidad en el ejercicio de tales funciones, permanencia o continuidad que excluyen una intervención puntual en la gestión de la sociedad; c) cierta calidad en el ejercicio de dichas funciones, con exclusión de este concepto a aquellos cuya actuación se quede en la esfera previa a la decisión, lo que no es sino consecuencia del requisito de la autonomía de decisión”. Por tanto, autonomía, habitualidad y calidad en el ejercicio de

\footnotetext{
${ }^{13}$ Cfr., entre otros, Embid Irujo, M. "La responsabilidad de los administradores en la sociedad anónima tras la Ley de Transparencia”, Revista Crítica de Derecho Inmobiliario, nº 685. 2004, págs. 2.379 y ss.

14 Sección Primera de la Sala de lo Penal del Tribunal Supremo: Sentencia núm. 606/2010, de 25 de junio (RJ 2010/7169); Sentencia 816/2006, de 26 de julio (RJ 2006/7317); Sentencia 59/2007, de 26 de enero (RJ2007/1586); Sentencia 480/2009, de 22 de mayo (RJ2010/662); Sentencia 986/2009, de 13 de octubre (RJ 2009/5991).
}

15 Auto núm. 155/2009 de 18 de septiembre de la Sección 15a de la Audiencia Provincial de Barcelona (AC 2009/2227); Sentencia de la Audiencia Provincial de La Rioja 504/2010, de 27 de diciembre (AC 2011/802); Sentencia de la Audiencia Provincial de La Rioja 1/2011, de 5 de enero (AC 2011/240); Sentencia de la Audiencia Provincial de La Coruña, Sección Cuarta, núm. 312/2011, de 6 de julio (JUR 2011/319319); Sentencia del Juzgado de lo Mercantil núm. 1 de Las Palmas de Gran Canaria, núm. 136/2011, de 18 de julio (JUR 2011/275524). 
las funciones serían las notas características que de existir en la persona que actúa en nombre de una sociedad, pueda ésta ser considerada administrador de hecho aunque no exista un nombramiento formal inscrito en el Registro Mercantil correspondiente.

Actualmente, el legislador, a través de la Ley 31/2014, sí introduce una definición legal del administrador de hecho que en nuestra opinión refleja las principales características ya señaladas por la jurisprudencia y a las que hemos hecho referencia con anterioridad. Concretamente, al regular la extensión subjetiva de la responsabilidad del administrador, señala en el art. 236.3 que “... tendrá la consideración de administrador de hecho tanto la persona que en la realidad del tráfico desempeñe sin título, con un título nulo o extinguido, o con otro título, las funciones propias del administrador, como, en su caso, aquellas cuyas instrucciones actúen los administradores de la sociedad.”. Igualmente, continúa indicando el siguiente apartado del mismo precepto que "Cuando no exista delegación permanente de facultades del consejo en uno o varios consejeros delegados, todas las disposiciones sobre deberes y responsabilidad de los administradores serán aplicables a la persona, cualquiera que sea su denominación, que tenga atribuidas facultades de más alta dirección de la sociedad, sin perjuicio de las acciones de la sociedad basadas en su relación jurídica con ella."

Es muy común en las sociedades, con la intención de agilizar su operativa diaria, que el administrador o administradores otorguen poderes de representación a otras personas como puede ser el gerente u otro alto cargo de la entidad para que represente a ésta ante la administración, entidades financieras, proveedores, clientes, etc. Dependerá de la capacidad de actuación que conceda ese poder al apoderado el hecho de que, en un momento determinado, pueda ser considerado administrador de hecho y, por tanto, susceptible de incurrir en la misma responsabilidad que el administrador de derecho si en su actuación concurren los presupuestos aludidos y desarrollados en el apartado anterior. Así, si nos encontramos la concesión de un poder absoluto de representación, que permite al apoderado actuar con total libertad e independencia en nombre y representación de la sociedad, estaría ocupando una posición muy próxima a la del administrador que le podrían ocasionar unas consecuencias similares en el supuesto de incurrir en responsabilidad. Si, por el contrario, el poder concedido al apoderado es un poder limitado a determinados actos o a un límite en el importe de las operaciones, sería más complicado para la parte actora demostrar los requisitos exigidos de autonomía, habitualidad y calidad en el ejercicio de las funciones del gerente para considerarlo 
administrador de hecho y así intentar derivarle la responsabilidad exigida a los administradores de derecho.

En este sentido, debemos resaltar que la Ley 31/2014 señala en el apartado 5 del art. 236 LSC indica que cuando una persona jurídica es la que ejerce las funciones propias de administrador, la persona física, que la representa en el cargo, estará sometida a los mismos deberes de los administradores y responderá solidariamente con la persona jurídica administrador ${ }^{16}$.

\section{B) Solidaridad. Causas de exoneración de la responsabilidad.}

El artículo 237 LSC, que no ha sido reformado por la Ley 31/2014 establece que "todos los miembros del órgano de administración que hubiera adoptado el acuerdo o realizado el acto lesivo responderán solidariamente, salvo los que prueben que, no habiendo intervenido en su adopción y ejecución, desconocían su existencia o conociéndola, hicieron todo lo conveniente para evitar el daño o, al menos, se opusieron expresamente a aquél'. El precepto señala con claridad el carácter solidario de la responsabilidad de los miembros del órgano de administración de una sociedad de capital y, por ello, el legitimado activo podrá dirigirse contra uno, algunos o todos los miembros que lo componen.

Pues bien, debido a ese carácter solidario de la responsabilidad y dado el riguroso régimen de responsabilidad instaurado por la $\mathrm{LSC}$, se comprende como también comentan Broseta Pont, M. y Martínez Sanz, F., la enorme trascendencia que adquieren las posibilidades de quedar exonerado ${ }^{17}$. El propio artículo 237 transcrito, señala la

\footnotetext{
${ }^{16}$ Redacción dada por la Ley 31/2014 del artículo 236.5 LSC "La persona física designada para el ejercicio permanente de las funciones propias del cargo de administrador persona jurídica deberá reunir los requisitos legales establecidos para los administradores, estará sometida a los mismos deberes y responderá solidariamente con la persona jurídica administrador".

Vid, entre otros, Juste Mencía, J., "En torno a la aplicación del régimen de responsabilidad de los administradores al apoderado general de la sociedad”. Revista de derecho de sociedades $n^{\circ} 14.2000$, págs. 441 y ss.; Latorre Chiner, N. El administrador de hecho en las sociedades de capital. Granada, 2003; Domíngues Ruiz de Huidobro, A. "Cuestiones sobre la responsabilidad de los administradores en los grupos de sociedades. Particular referencia a la teoría del administrador de hecho. Est. Hom. Sánchez Calero, II, págs. 1299 y ss; Fuentes Naharro, M. "Una aproximación al concepto de administrador de hecho y a la funcionalidad de la figura en los grupos de sociedades", en gobierno Corporativo y crisis empresariales. Madrid 2006, págs. 289 y ss.

${ }^{17}$ Broseta Pont, M. y Martínez Sanz, F. Manual de Derecho Mercantil. Madrid 2014, op. cit., pág. 507.
} 
posible exoneración de esa responsabilidad de algunos de los miembros del órgano de administración señalando tres casos:

a) Cuando el administrador no estuviese presente en la reunión donde se adoptó el acuerdo lesivo y desconozca su existencia. Este desconocimiento, en opinión de la doctrina mayoritaria, se refiere tanto al momento anterior a la reunión como al posterior. En este mismo sentido se posicionan Broseta Pont, M. y Martínez Sanz, F. al señalar que a la ausencia del administrador en el momento de la toma del acuerdo que produce el daño ha de exigirse que no haya tomado parte en la posterior ejecución del mismo pues entienden que con ello estaría ratificándolo $^{18}$. Añaden también que recae sobre el administrador la carga de la prueba de que desconocía la existencia del acuerdo.

b) Que en el supuesto de que el administrador conozca la existencia del acuerdo lesivo, hizo todo lo conveniente para evitar el daño.

c) Que el miembro del órgano de administración, al menos, se opusiera expresamente al acuerdo lesivo. Esa "oposición expresa" hace pensar que no bastará con abstenerse y con salvar el voto sino que será necesario haber votado en contra solicitando que se refleje la oposición en el acta de la junta en la que se debate el acuerdo.

A estos supuestos de exoneración de la responsabilidad, que permiten eludir el régimen de responsabilidad tan severo al que venimos aludiendo, se añade aquel en el que el propio administrador manifiesta su voluntad de cesar como miembro del órgano de la sociedad a través de notificación fehaciente firmada ante Notario y comunicada por éste a la sociedad. En este caso, los terceros de buena fe ajenos a la sociedad pueden no haber tenido conocimiento del cese si los administradores que continúan en el ejercicio de su cargo no han realizado los trámites necesarios para su inscripción en el Registro Mercantil correspondiente. En opinión de Broseta Pont, M. y Martínez Sanz, F. aunque los terceros puedan seguir considerando a esa persona como administrador, pues en el Registro sigue apareciendo como tal $\mathrm{y}$, en principio podrían demandarlo, ha de

García Villaverde, R. Exoneración de la responsabilidad civil de los administradores de la sociedad anónima y de la responsabilidad limitada por falta de culpa. Sánchez Calero II, págs. 1.321 y ss.

${ }^{18}$ Broseta Pont, M. y Martínez Sanz, F., Manual de Derecho Mercantil. Madrid, 2014, op. cit., pág. 507.

Vid, entre otros, Gallego Sánchez, E., Derecho Mercantil. Parte Primera. Valencia, 2015, págs. 479 y ss. 
considerarse que será de aplicación la causa de exoneración prevista en el art. 237 LSC por no haber intervenido en su adopción y desconocer su existencia ${ }^{19}$.

Es cuestión controvertida determinar el momento en el que el administrador deja de ser responsable solidario por los actos realizados por el resto de miembros del consejo de administración. Nos referimos expresamente al tiempo que transcurre entre el momento en que el administrador manifiesta ante Notario su voluntad de cesar en el cargo y el momento mismo de la inscripción. El criterio de la administración es considerar responsable solidario a ese administrador por los actos realizados en ese espacio de tiempo. Sin embargo, la línea del la jurisprudencia del Tribunal Supremo es contraria a la opinión de la administración, al declarar que las inscripciones regístrales de los acuerdos de cese no tienen carácter constitutivo, al no imponerlo así precepto alguno, correspondiendo el deber de inscribir a los nuevos administradores, sin que ninguna responsabilidad por falta de inscripción pueda exigirse a los cesados” ${ }^{20}$. Cuestión distinta es la doctrina del Tribunal Supremo ${ }^{21}$ sobre la oponibilidad a terceros de los actos sujetos a inscripción y no inscritos que lo plantea como un problema de eficacia respecto de la sociedad de actuaciones o gestiones realizadas por los administradores no inscritos, o que permanecen inscritos después de su cese, sobre todo porque en el primer caso la permanencia de la inscripción registral del administrador, que ya ha cesado, no ha sido determinante ni influyente en la relación de la sociedad y el acreedor que reclama.

No obstante lo anterior, expresamente la LSC en su artículo 236.2 señala que en ningún caso será causa de exoneración de la responsabilidad del administrador el hecho de que el acto o acuerdo lesivo haya sido adoptado, autorizado o ratificado por la junta general. En opinión de Sánchez Calero, F. y Sánchez-Calero Guilarte, J. "la Ley ha querido establecer una independencia o autonomía de la actuación del órgano de administrativo con relación a los acuerdos de la Junta General, en el sentido de que los administradores no deben realizar actos lesivos para la sociedad, aún cuando exista un acuerdo de Junta general que lo autorice. Igualmente los administradores no pueden esperar que se sane la ilicitud de su conducta por medio de un acuerdo de la Junta

\footnotetext{
${ }^{19}$ Broseta Pont, M. y Martínez Sanz, F., Manual de Derecho Mercantil. Madrid, 2014, op. cit., pág. 508.

${ }^{20}$ V. SSTS de fecha de 10 de mayo de 1999, 23 de diciembre de 2002, 24 de diciembre de 2002, 16 de julio de 2004, 28 de mayo de 2005, 7 de febrero de 2007 y 22 de marzo de 2007.

${ }^{21}$ V. SSTS de fecha 28 de abril de 2006.
} 
general. Tampoco será suficiente, para la exoneración de la responsabilidad de los administradores, que su actuación se deba a la ejecución de un acuerdo de la Junta

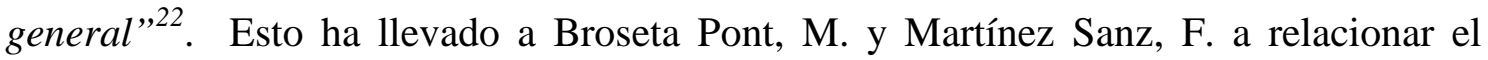
artículo 236.2 de la LSC con el 161 del mismo texto legal que establece que las decisiones de la junta general no puedan ser eludidas por los administradores y señalan que "no sería muy lógico, por tanto, exigirles responsabilidad (al menos por la propia sociedad, en virtud de la doctrina de los <<actos propios >>) por llevar a cabo un acto o acuerdo dañoso para la sociedad que se derive de una instrucción impartida por la propia Junta general, la cual, como sabemos, resulta plenamente vinculante para los administradores de una sociedad de este tipo" ${ }^{, 23}$.

Por lo expuesto, en los casos en los que el acuerdo adoptado por la junta general no se corresponde con la actuación que ha de seguir el administrador para cumplir con los deberes que le han impuesto, consideramos que la postura más prudente y segura de actuar por parte del administrador es presentar de inmediato su cese en el cargo. Así, evita su responsabilidad personal y las consecuencias que le pueden llegar a suceder, como es responder con su patrimonio personal para resarcir el daño producido por su actuación. De lo contrario, podría verse como parte demandada en un procedimiento de derivación de responsabilidad o, si la sociedad termina en un procedimiento de concurso de acreedores, su actuación se evaluaría en la pieza sexta de calificación.

\section{III.- Acción social de responsabilidad. Prescripción.}

La Ley distingue entre la acción social e individual de responsabilidad, en función de que el patrimonio directamente dañado por el acto de los administradores sea el de la sociedad o el de los socios o terceros.

La acción social de responsabilidad, regulada en el artículo 238 de la LSC, salvaguarda los intereses sociales y, por tanto, para ejercitar esta acción se requiere que el daño se haya causado a la sociedad. Están legitimados para ejercitar la acción social de responsabilidad, en primer lugar, la propia sociedad; y con carácter subsidiario, los accionistas, y, por último, los acreedores.

\footnotetext{
22 Sánchez Calero, F. / Sánchez-Calero Guilarte, J., Instituciones de Derecho Mercantil. Volumen I. Navarra, 2013. Op. cit., pág. 533.

${ }^{23}$ Broseta Pont, M. y Martínez Sanz, F., Manual de Derecho Mercantil. Madrid, 2014, op. cit., pág. 507.
} 
Es requisito imprescindible que, la sociedad, para poder instar la acción de responsabilidad contra los administradores, cuente con un acuerdo previo de la Junta General que puede ser adoptado a solicitud de cualquier socio aunque no conste en el orden del día y siendo suficiente, como marca el art. 238 de la LSC, la mayoría ordinaria de accionistas de cualquier Junta general sin que sea válido que los estatutos fijen una mayoría calificada. Ahora bien, siempre que no se opusieran a ello socios que representen el 5 por 100 del capital social la Junta general en cualquier momento puede renunciar al ejercicio de la acción, aunque el administrador afectado no volverá a obtener el cargo.

Si la acción social no fuera instada por la sociedad, la Ley establece un sistema de legitimación “en cascada” o subsidiaria según palabras de Broseta Pont, M. y Martínez Sanz, F. ${ }^{24}$ estando legitimados para entablarla el socio o socios que posean individual o conjuntamente una participación que les permita solicitar la convocatoria de junta general, en defensa del interés social, en los siguientes supuestos contemplados en el art. 239.1, primer párrafo de la LSC:

a) Cuando solicitada la convocatoria de la Junta general con el fin de que decida sobre el ejercicio de la acción de responsabilidad, ésta no fuera convocada por los administradores;

b) Cuando la sociedad no entablare la acción de responsabilidad, dentro del plazo de un mes, contado desde la fecha de adopción del correspondiente acuerdo;

c) Cuando éste hubiera sido contrario a la exigencia de responsabilidad.

A este art.239.1 le ha sido añadido por la Ley 31/2014 un segundo párrafo que legitima a ejercitar directamente la acción social de responsabilidad, sin necesidad de someter la decisión a la junta general, al socio o socios que posean individual o conjuntamente una participación que les permita solicitar la convocatoria de junta general cuando se fundamente en la infracción del deber de lealtad. Igualmente, la Ley 31/2014 da un redacción nueva al apartado 2 del art.239 de la LSC, que tiene un marcado interés en la práctica procesal, pues obliga expresamente a la sociedad, en caso de estimación total o

\footnotetext{
${ }^{24}$ Broseta Pont, M. y Martínez Sanz, F., Manual de Derecho Mercantil. Madrid, 2014, op. cit., págs.508 y ss. Vid, entre otros, Gallego Sánchez, E., Derecho Mercantil. Parte Primera. Valencia, 2015, op. cit., pág. 480 ss.
} 
parcial de la demanda, a reembolsar a la parte actora los gastos necesarios en los que hubiera incurrido "con los límites previstos en el artículo 394 de la Ley 1/2000, de 7 de enero, de Enjuiciamiento Civil, salvo que esta haya obtenido el reembolso de estos gastos o el ofrecimiento de reembolso de los gastos haya sido incondicional”.

Cuando la acción social no haya sido ejercitada por la sociedad o sus socios, podrán ejercitarla los acreedores de la sociedad siempre que el patrimonio social resulte insuficiente para la satisfacción de sus créditos ${ }^{25}$. Hay dos aspectos a tener en cuenta en el ejercicio de esta acción por los acreedores: a) el plazo que han de concederle a los otros legitimados, sociedad y socios, donde la Ley no establece qué plazo han de esperar los acreedores para considerar que ha llegado "su turno" una vez no ha sido instada la acción por la sociedad o sus socios, si bien es verdad que hay un plazo aceptado por doctrina y jurisprudencia que es de un mes, salvo, cuando se detecte ausencia de actuaciones de la sociedad y de los socios, que no resulta lógico concederle plazo alguno; b) como señala expresamente el art. 240 LSC es necesario que el patrimonio social resulte insuficiente para la satisfacción de sus créditos, lo cual nos coloca en una situación preconcursal o abiertamente concursal como acertadamente señalan Broseta Pont, M. y Martínez Sanz, F. ${ }^{26}$

Resuelta queda la duda que en otros tiempos ha ocupado los pronunciamientos de doctrina y jurisprudencia sobre el plazo de prescripción de esta acción, con la inclusión por la Ley 31/2014 del nuevo artículo 241 bis que señala expresamente y con total claridad que el plazo de prescripción de las acciones de responsabilidad, tanto social como individual a la que aludiremos en el siguiente apartado, es de cuatro años fijando el diez a quo en el día en que hubiera podido ejercitarse ${ }^{27}$.

\section{IV.- Acción individual de responsabilidad. Prescripción.}

\footnotetext{
${ }^{25}$ Artículo 240 de la LSC “Los acreedores de la sociedad podrán ejercitar la acción social de responsabilidad contra los administradores cuando no haya sido ejercitada por la sociedad o sus socios, siempre que el patrimonio social resulte insuficiente para la satisfacción de sus créditos".

${ }^{26}$ Esta acción social de responsabilidad tiene la finalidad de de reparar o resarcir el daño causado en la sociedad por los actos o las omisiones de los administradores, por tanto, cuando es instada por los socios o por los acreedores no reclaman para ello sino que reclaman para la sociedad. En este sentido, V. STS de 21 de mayo de 1985 (RJ2406). Broseta Pont, M. y Martínez Sanz, F., Manual de Derecho Mercantil. Madrid 2014, op. cit., págs.508 y ss.

27 Art. 241 bis de la LSC "La acción de responsabilidad contra los administradores, sea social o individual, prescribirá a los cuatro años a contar desde el día en que hubiera podido ejercitarse”.
} 
La acción individual de responsabilidad está regulada en el art. 241 de la LSC y se insta cuando se han lesionado directamente los intereses de los socios o de los terceros por actos de los administradores, a diferencia de lo que sucede cuando se ejercita la acción social que, como hemos visto, el daño se produce a la sociedad. Esta distinción en la práctica no resulta siempre tan clara.

Siguiendo lo escrito por Sánchez Calero, F. y Sánchez-Calero Guilarte, J. ${ }^{28}$ vamos a indicar los presupuestos que se han de dar de manera obligatoria para poder entablar la acción individual de responsabilidad contra los administradores:

a) tiene que producirse un daño directo a los socios o a los terceros;

b) que se trate de un acto de los administradores en el ejercicio de su cargo;

c) ilicitud de la acción u omisión de los administradores, que se ha medido por la jurisprudencia con los mismos cánones que en el caso de la acción social, de manera que de seguir esta orientación habrá de aplicarse el art. 236 LSC;

d) relación de causalidad entre el acto ilícito del administrador y el daño sufrido por el socio o el tercero, recayendo sobre esto la carga de probar que el daño ha sido motivado por hechos, actos u omisiones dolosas o culposas del administrador.

Aunque es cierto como señalan Broseta Pont, M. y Martínez Sanz, F. ${ }^{29}$ que la acción individual ha adquirido mucha relevancia por la cantidad de acreedores de las sociedades que la entablan, también es cierto que cada vez más estas reclamaciones se encauzan por los supuestos de art. 367 LSC, al que nos referiremos en el apartado siguiente. El motivo fundamental es la carga de la prueba, siendo más importante la que recae en la parte actora en la acción individual de responsabilidad, que como hemos visto está obligada a demostrar la relación de relación de causalidad entre el acto ilícito del administrador y el daño sufrido por el socio o el tercero ${ }^{30}$.

Sobre el plazo de prescripción de esta acción individual, se han venido pronunciando los autores a lo largo de los años, intentando diferenciar si nos encontrábamos ante una

\footnotetext{
${ }^{28}$ Sánchez Calero, F. / Sánchez-Calero Guilarte, J., Instituciones de Derecho Mercantil. Volumen I. Navarra, 2013, op. cit., pág.535.

${ }^{29}$ Broseta Pont, M. y Martínez Sanz, F., Manual de Derecho Mercantil. Madrid, 2014, op. cit., pág.509

${ }^{30}$ V. SSTS de 4 de noviembre de 1991, RJ8143; y, sobre todo, de 21 de mayo de 1992, (RJ 4274).
} 
responsabilidad contractual o en el campo de la responsabilidad extracontractual. La jurisprudencia, restándole importancia a la naturaleza de la responsabilidad, ya se había definido, siguiendo el art. 949 del Código de Comercio, por un plazo de prescripción de cuatro años a contar desde el momento en que cesó el administrador en el ejercicio de sus funciones. El problema está resuelto definitivamente desde que la Ley 31/2014, como hemos comentado más arriba, incluyó en la LSC el nuevo art. 241 bis que señala como plazo de prescripción tanto de la acción social como de la acción individual cuatro años. Sí se modifica el diez a quo que cambia del establecido por la jurisprudencia en el momento en el que el administrador cesa en sus funciones, pasando a ser el día en que hubiera podido ejercitarse una u otra acción de responsabilidad.

\section{V.- Supuesto de responsabilidad del art. 367.1 de la Ley de Sociedades de Capital.}

Además de los supuestos de responsabilidad contemplados en el art. 236 y regulados en los arts. 237 a 241 de la LSC los administradores de las sociedades de capital, en determinados casos, pueden verse obligados a responder con su patrimonio personal de deudas de la sociedad. En este sentido el art. 367.1 de la LSC establece que "responderán solidariamente de las obligaciones sociales posteriores al acaecimiento de la causa legal de disolución los administradores que incumplan la obligación de convocar en el plazo de dos meses la junta general para que adopte, en su caso, el acuerdo de disolución, así como los administradores que no soliciten la disolución judicial o, si procediere, el concurso de la sociedad, en el plazo de dos meses a contar desde la fecha prevista para la celebración de la junta, cuando ésta no se haya constituido, o desde el día de la junta, cuando el acuerdo hubiera sido contrario a la disolución".

Por lo expuesto en el precepto, los administradores tendrán que responder de las obligaciones sociales cuando no procedan a la disolución de la sociedad en los casos mencionados en el art. 363 de la LSC, que son los siguientes:

a) Por el cese en el ejercicio de la actividad o actividades que constituyan el objeto social. En particular, se entenderá que se ha producido el cese tras un periodo de inactividad superior a un año.

b) Por la conclusión de la empresa que constituya su objeto 
c) Por la imposibilidad manifiesta de conseguir el fin social

d) Por la paralización de los órganos sociales de modo que resulte imposible su funcionamiento.

e) Por pérdidas que dejen reducido el patrimonio neto a una cantidad inferior a la mitad del capital social, a no ser que se aumente o se reduzca en la mitad suficiente, y siempre que no sea procedente solicitar la declaración de concurso.

f) Por reducción del capital social por debajo del mínimo legal, que no sea consecuencia del cumplimiento de una ley.

g) Porque el valor nominal de las participaciones sociales sin voto o de las acciones sin voto excediera de la mitad del capital social desembolsado y no se restableciera la proporción en el plazo de dos años.

h) Por cualquier otra causa establecida en los estatutos".

Si se da una de las causas legales de disolución el administrador tiene el deber de convocatoria en los plazos establecidos en el art. 236 de la LSC, es decir, el de dos meses para que adopte el acuerdo de disolución o, si la sociedad fuera insolvente, para que ésta inste el concurso de acreedores.

Respecto a qué deudas son susceptibles de derivar la responsabilidad al administrador, la Ley de Sociedades de Capital señala expresamente que serán las posteriores a la generación de alguna de las causas de disolución mencionadas anteriormente ${ }^{31}$.

Continúa el artículo 367.1 de la LSC con el supuesto concursal "los administradores que no soliciten la disolución judicial o, si procediese, el concurso de la sociedad...", es decir, que existiendo causa de disolución por insuficiencia patrimonial, la vía del concurso tiene preferencia en caso de insolvencia sobre la de disolución de la sociedad con el fin de amparar los intereses de los acreedores.

El administrador, en esta situación, deberá acreditar la convocatoria de la junta general o la comunicación fehaciente a los socios de las circunstancias de la empresa y las consecuencias y las recomendaciones legales. En el caso de que no se acuerde lo

\footnotetext{
${ }^{31}$ Artículo 367.1 de la LSC "Responderán solidariamente de las obligaciones sociales posteriores al acaecimiento de la causa legal de disolución los administradores que incumplan la obligación de convocar en el plazo de dos meses la junta general para que adopte, en su caso, el acuerdo de disolución, así como los administradores que no soliciten la disolución judicial o, si procediere, el concurso de la sociedad, en el plazo de dos meses a contar desde la fecha prevista para la celebración de la junta, cuando ésta no se haya constituido, o desde el día de la junta, cuando el acuerdo hubiera sido contrario a la disolución".
} 
recomendado legalmente, se sugiere solicitar la disolución de la sociedad o el concurso de acreedores. Y si ninguna de las anteriores se lleva a cabo, se deberá presentar como señalábamos anteriormente, la dimisión por parte del administrador y su publicación en el Registro Mercantil, pues puede ser contraproducente, para eximir la responsabilidad, continuar siendo administrador de una sociedad que no cumple los preceptos legales.

Este supuesto de responsabilidad es el que utiliza mayoritariamente la Administración para intentar hacer responder al administrador, con su patrimonio personal presenta y futuro, de las deudas de la sociedad que representa. Por esta razón, son numerosos los pronunciamientos de la jurisprudencia, de los que considero apropiado resaltar las sentencias de la Sala 1a del TS de 10 de noviembre de 2010 EDJ 2010/258985 y de 23 de diciembre de 2011 EDJ 2011/328375 que señalan con claridad los requisitos que han de darse para que surja el deber del administrador de responder por deudas sociales ( artículos 262.5 del TRLSA EDL 1989/15265, 105.5 de la LSRL EDL 1995/13459 y 367 del vigente TRLSC) ${ }^{32}$ :

1) existencia de crédito contra la sociedad (posterior al acaecimiento de la causa de disolución) pues se trata de una acción reservada a los acreedores de la sociedad;

2) concurrencia de alguna de las causas de disolución de la sociedad, previstas en la propia legislación societaria;

\footnotetext{
${ }^{32}$ Para profundizar en el estudio del supuesto de responsabilidad del administrador contemplado en el artículo 367.1 de la LSC, Vid. entre otros: Machado Plazas, J. La naturaleza jurídica de la responsabilidad por las deudas sociales y la cuestión relativa a la aplicación retroactiva del artículo 367 LSC. Estudios de Derecho Mercantil. (Coord. Sáenz García de Albizu, J.C., Oleo Banet, F., Martínez Flórez, A.), 2010, págs. 785 y ss.; Moya Jiménez, A. La responsabilidad de los administradores de empresas insolventes. Barcelona, 2006; Quijano González, J. "La responsabilidad de los administradores por la no disolución de la sociedad y las causas de exoneración”. Revista de derecho se sociedades. $\mathrm{N}^{\circ} 19.2002$, págs. 73 y ss.;

Igualmente, indicamos jurisprudencia sobre esta materia: TSJ de Murcia, Sala de lo Contencioso-Administrativo, sec. $1^{\mathrm{a}}$, S 5-7-2013, no 568/2013, rec. 742/2008; Jdo. de lo Mercantil n ${ }^{\circ}$ 1, Granada, S 2-5-2013, nº 133/2013, $\mathrm{n}^{\circ}$ autos 528/2012; AP Alicante, sec. 8 , S 3-4-2013, no 154/2013, rec. 26/2013; AP Madrid, sec. 28 ${ }^{\text {a }, ~ S ~ 8-2-2013, ~ n o ~ 42 / 2013, ~}$ rec. 765/2011; AP Cantabria, sec. 2a , S 21-2-2013, n ${ }^{\circ}$ 109/2013, rec. 633/2011; AP Madrid, sec. 28 ${ }^{\text {a }}$, S 7-12-2012, ${ }^{\circ}$ 385/2012, rec. 614/2011; AP Madrid, sec. 28 a S 14-6-2012, n 190/2012, rec. 509/2011; Jdo. de lo Mercantil no 2, Bilbao, S 23-4-2012, $n^{\circ}$ 107/2012, $n^{\circ}$ autos 501/2010; Jdo. de lo Mercantil n ${ }^{\circ}$ 2, Bilbao, S 20-1-2012, $n^{\circ} 8 / 2012, n^{\circ}$ autos 13/2011; AP Madrid, sec. 28 , S 13-1-2012, no 7/2012, rec. 201/2011; AP Madrid, sec. 28 a , S 12-9-2011, nº 248/2011, rec. 17/2011; AP Madrid, sec. 28 , S 9-4-2010, no 88/2010, rec. 220/2009; TSJ de Murcia, Sala de lo Contencioso-Administrativo, sec. $1^{\text {a }}$, S 19-2-2010, $\mathrm{n}^{\text {o }}$ 128/2010, rec. 613/2005; Audiencia Nacional Sala de lo Contencioso Administrativo, sec. 6a, S 16-6-2003, rec. 219/2000.
}

Universidad de Almería - Edificio Departamental de Ciencias Jurídicas - (Edif. D) Planta. 2, Despacho: 2.210 Ctra. Sacramento s/n - La Cañada de San Urbano 04120 Almería 
3) omisión por los administradores de la convocatoria de junta general para la adopción de acuerdos de disolución o de remoción de sus causas;

4) transcurso de dos meses desde que concurriese la causa de disolución;

5) imputabilidad al administrador de la conducta pasiva; y

6) inexistencia de causa justificadora de la omisión.

\section{VI.- Responsabilidad en el ámbito concursal.}

En el procedimiento concursal también los administradores pueden verse en la situación de tener que responder frente a los acreedores sociales pos las deudas de la mercantil concursada. Este hecho se examina mediante en una pieza separada dentro del procedimiento concursal con objeto de investigar las causas que han provocado la situación de insolvencia de la concursada. Así, si se abre la sección de calificación, ésta puede finalizar con la condena de todos o algunos de los administradores de derecho o de hecho de la sociedad deudora a hacer frente con su patrimonio personal a soportar el déficit existente.

Para Cruz Rivero, D. ${ }^{33}$ esta responsabilidad tiene naturaleza sancionadora, a diferencia de la ya comentada en este artículo y regulada en los arts. 236 y ss. LSC que tiene carácter indemnizatorio. La responsabilidad concursal tiene por finalidad cubrir la insuficiencia de la masa y se requiere como presupuesto dolo o culpa grave en la actuación del administrador durante los dos años anteriores a la declaración de concurso.

Ahora bien, hay determinados casos en los que la Ley Concursal (en adelante LC) establece presunciones iuris tantum de dolo o culpa grave (art.165 LC), y otros presupuestos a los que otorga presunción iure et de iure de culpabilidad (art.164.2 LC) siendo en la práctica estas presunciones las que justifican la mayor parte de los supuestos de culpabilidad de los concursos. Según la doctrina sólo procede la declaración de culpabilidad del concurso cuando concurra un acto u omisión del administrador en el que pueda determinarse dolo o culpa grave y exista una relación

\footnotetext{
33 Cruz Rivero, D., La administración de la sociedad en Derecho Mercantil. Las sociedades mercantiles. (Coord. Jiménez Sánchez, G.J. y Díaz Moreno, A.) Madrid 2013, op. cit., pág. 550. 
causal entre esa actuación y la generación o agravación del estado de insolvencia que ha provocado el inicio del procedimiento concursal

Finalmente será una sentencia la que califique el concurso como culpable o fortuito. De declararse culpable, la sentencia debe estar motivada y señalar las personas afectadas por la calificación indicando igualmente si la condena consiste en una inhabilitación de funciones o va más allá exigiendo al administrador responder con su patrimonio personal del déficit patrimonial generado, siendo esta última consecuencia una situación especial y reservada para los casos más graves. Se trata del instrumento más severo que regula la Ley, en cuanto a su alcance objetivo, al poder llevar aparejada la condena la exigencia de responder por la totalidad del pasivo concursal no cubierto en la liquidación y subjetivo al recaer sobre los administradores actuales o anteriores, con el límite de dos años ${ }^{34}$.

Recientemente se ha modificado el art.172.bis, apartado 1, por la nueva redacción del art.uno.12 de RDL 4/2014 de 7 marzo $2014^{35}$ y por ello, desde el 9-3-2014, los socios de una sociedad en concurso que hayan sido declarados como personas afectadas por la calificación, cuando se hayan negado sin causa razonable a la capitalización de créditos o una emisión de valores o instrumentos convertibles, y con ello se frustre la consecución de un acuerdo de refinanciación, pueden llegar a responder del pasivo concursal no cubierto en la fase de liquidación. Quedará al arbitrio del juez del concurso la aplicación o no de esta responsabilidad por deudas, y, en caso de aplicarla, debe hacer un análisis individualizado de la participación de cada una de las personas afectadas por la calificación, graduando la condena según la participación en los hechos que hubieran determinado la calificación del concurso como culpable ${ }^{36}$.

\footnotetext{
${ }^{34}$ Para profundizar en el estudio de la responsabilidad del administrador de una sociedad de capital en situación de concurso de acreedores, Vid., entre otros: Velasco, E. La responsabilidad de los administradores. Coords. Rojo y Beltrán. Valencia, 2005; Alonso Ureba. La responsabilidad concursal de los administradores en la sociedad de capital en situación concursal. AA.VV. (Directores, García Villaverde, Alonso Ureba y Pulgar Ezquerra). Derecho concursal. Estudio sistemático de la Ley 22/2003 y de la Ley 8/2003 para la Reforma Concursal. Madrid. 2003. págs. 505 y ss.; Fernández de la Gándara. Comentario a la Ley Concursal. Madrid, 2004.

${ }^{35}$ V. entre otras la Sentencia del Juzgado de lo Mercantil de Granada de fecha 13 de marzo de 2015 (JUR 2015/106359).

${ }^{36}$ Es en este sentido, se pronuncia el Tribunal Supremo, Sala Primera, de lo Civil, Sentencia 45/2015 de 5 Feb. 2015, Rec. 1086/2013 donde condena al administrador societario a la cobertura parcial del déficit concursal, señalando
} 


\section{VII.- Responsabilidad de la sociedad en formación.}

En todo proceso de constitución de una sociedad transcurre un espacio de tiempo desde que se otorga la escritura pública de constitución de la sociedad hasta que ésta se inscribe en el Registro Mercantil correspondiente. En este periodo, la Ley de Sociedades de Capital señala claramente las personas sobre las que recae la responsabilidad por los actos realizados en nombre de la sociedad y hasta qué momento.

Así, por los actos y contratos celebrados en nombre de la sociedad antes de su inscripción en el Registro Mercantil responderán solidariamente quienes lo hubiesen celebrado salvo que el acuerdo estuviera condicionado a la inscripción y, en su caso, posterior asunción de los mismos por la sociedad ${ }^{37}$. Igualmente, responderá la sociedad en formación con el patrimonio que tuviere y los socios personalmente hasta el límite que se hubieran comprometido a aportar, por los actos necesarios para la inscripción de la sociedad, por las actuaciones de los administradores dentro de las facultades concedidas y por las realizadas por las personas específicamente designadas por todos los $\operatorname{socios}^{38}$.

Será, como señala el art. 38 LSC, con la definitiva inscripción de la sociedad en el Registro Mercantil cuando quede obligada por todos los actos y contratos celebrados por los socios, administradores o personas específicamente designadas y cesará, desde ese momento, la responsabilidad soldaría de todos ellos.

\section{VIII.- CONCLUSIONES}

Los administradores de las sociedades de capital han visto como a lo largo de las distintas regulaciones legales se han ido flexibilizando los requisitos exigidos para derivarles responsabilidad pasando de exigir que el daño lo hayan causado con malicia, abuso de facultades o negligencia grave a simplemente requerir que el acto sea contrario

\footnotetext{
expresamente que en el régimen anterior al Real Decreto-ley 4/2014, de 7 de marzo, no era necesaria la concurrencia de una relación de causalidad entre la conducta del administrador o liquidador determinante de la calificación del concurso como culpable y el déficit concursal del que se hacía responsable a dicho administrador o liquidador, finalizando con que "La sentencia recurrida no ha vulnerado por tanto la jurisprudencia de esta Sala. Ha tomado en consideración la gravedad de la conducta determinante de la calificación del concurso como culpable, y la participación en ella del hoy recurrente, que era el administrador único de la sociedad concursada y única persona afectada por la declaración del concurso como culpable", es donde establece la naturaleza y relación de causalidad.

${ }^{37}$ Ver artículo 36 de la LSC.

${ }^{38}$ Ver artículo 37 de la LSC.
} 
a la Ley, los estatutos o realizado sin la diligencia con la que deben desempeñar el cargo. Igualmente, se extendió el ámbito subjetivo de esa responsabilidad alcanzando a los llamados administradores de hecho.

En este artículo nos hemos centrado en analizar el sistema de responsabilidad jurídicoprivada regulado en el Capítulo V del Título VI de la Ley de Sociedades de Capital y que ha sufrido una importante reforma con Ley 31/2014, de 3 de diciembre, por la que se modifica la Ley de Sociedades de Capital para la mejora del gobierno corporativo. Desde su entrada en vigor el 24 de diciembre de 2014, se han modificado, en lo referente a los deberes de los administradores, los artículos 225 a 230 y el 232 de la Ley de Sociedades de Capital y se ha incluido el nuevo artículo 241. bis del mismo texto legal referente a la prescripción de las acciones de responsabilidad que se pueden seguir contra los administradores. Consideramos de especial trascendencia práctica los presupuestos que ha de probar la parte que insta la acción social o individual de responsabilidad contra el administrador, que podríamos resumir en la existencia de una acción u omisión del administrador que produce un daño en la sociedad, sus socios o terceros, mediando relación de causalidad. Igualmente, debido al severo régimen de responsabilidad al que se someten los administradores y la solidaridad a la que están sometidos cuando se ejerce la administración mediante un consejo de administración, nos hemos centrado en la opinión de la doctrina y jurisprudencia acerca de las actuaciones que ha de llevar a cabo el administrador para quedar exonerado de responsabilidad, sin que sea suficiente que alegue su desconocimiento ${ }^{39}$. En este sentido, consideramos necesario para exculpar al administrador que éste hubiese impugnado el acuerdo que ha provocado el daño. También destacamos que, aunque la junta general hubiese adoptado el acuerdo, ello no exime de responsabilidad al administrador, siendo, en este caso, la postura más segura y prudente solicitar el cese en su cargo.

Le hemos dedicado un apartado específico a la responsabilidad regulada en el art. 367.1 de la LSC al ser uno de los principales motivos alegados por la administración en sus intentos de derivación de responsabilidad contra los administradores ya que sólo es necesario demostrar que la sociedad estaba en causa de disolución y el administrador no

\footnotetext{
${ }^{39}$ V. Exposición de motivos de la Ley 31/2014, de 3 de diciembre, por la que se modifica la Ley de Sociedades de Capital para la mejora del gobierno corporativo en su preámbulo $\mathrm{V}$ “... se establece la obligación de los consejeros de asistir personalmente a las sesiones del consejo...".
} 
adoptó las medidas requeridas en los plazos establecidos. Resulta de especial relevancia el tratamiento de la responsabilidad en el procedimiento concursal y la responsabilidad en las sociedades en formación, porque siempre hay un espacio de tiempo entre el otorgamiento de la escritura de constitución y su inscripción en el Registro Mercantil por lo que debemos conocer los responsables y hasta qué punto de los actos realizados durante ese periodo. 